\title{
Research on Implementation Situation of Accounting Standards for Small-sized Enterprises in Shandong Province
}

\author{
Jingmei Wang \\ Shandong Yingcai University, Ji'nan, 250014, China
}

\begin{abstract}
Keywords: accounting standard; small-sized enterprises; problems to which the attention shall be paid; solution

Abstract. In the process of enterprise development, the continuous rectification shall be made to add enterprise's vigor; as for small-sized enterprises, to implement corresponding accounting standard can realize specific effect. This author mainly carries out consideration and research on corresponding problems existing in the process of implementation of accounting standard of small-sized enterprises as well as various influence factors, summarizes fundamental reason of problems through survey and research, and compiles the problems which we shall pay attention to in the implementation process of accounting standard of small-sized enterprises and corresponding solutions. This paper carries out relevant analysis and discussion on the implementation situation of accounting standard of small-sized enterprises in Shandong Province.
\end{abstract}

\section{Introduction}

After implementation of accounting standard, the corresponding small-sized enterprises benefit and the problem in enterprise's short-term conduct is solved, which makes the management of small-sized enterprises become more stable. However, there also exist corresponding problems in the implementation process of accounting standard; for example, the early system is imperfect, the corresponding work staff makes use of system defect to carry out violation operation, the enterprise's corresponding management is not in place, and there is no mature integrated management and operation team. As for various drawbacks, the management department issues corresponding management rules and restrains work staff through relevant rules so as to make them handle affairs according to rules and regulations. The authority departments organize corresponding theory training courses as for the phenomenon that partial accounting personnel are not familiar with implementation of new accounting standard, establish corresponding diploma, and requires accounting personnel to obtain employment with certificate. The purpose of training is to deepen work staff's understanding of relevant theoretical knowledge, and enhance work staff's work skills. Shandong province is a province with numerous middle and small-sized enterprises; therefore, the implementation of accounting standard in small-sized enterprises in relevant cities in Shandong Province has certain representativeness, and then the summary and perfection is made for convenience of further promotion.

\section{Implementation situation of accounting standard of small-sized enterprises and formal analysis}

\subsection{Implementation situation}

The enterprises which implemented enterprise accounting standard in 2013 include 33 listed companies, excluding 42\% of Qingdao listed companies and Jinan Iron \& Steel (Group) Co., Ltd., etc. Among 3,972 surveyed enterprises, 1,531 enterprises (including 21 listed companies) have implemented new standard, with an implementation rate of $38.54 \%$. According to region, the implementation rate of Laiwu (69\%), Huaifang (50\%), Liaocheng (48\%), Heze (44\%), Weihai (44\%), Binzhou (42\%), and Yantai (40\%) is higher than average level of whole province; the implementation rate of Jining (27\%), Dezhou (19\%), Zaozhuang(15\%), and Tai'an (5\%) is lower than average level. According to industry, the industrial enterprises have an implementation rate of 39\%; the mining industry, manufacturing industry, gas and water production and supply industry, 
building industry, wholesale business, retail industry, transportation industry, accommodation and catering industry, and other enterprises have an implementation rate of $46 \%$, 38\%, 33\%, 42\%, $27 \%$, $33 \%$, 34\%, $24 \%$, and $17 \%$ respectively.

In 2010, Accounting Standards for Business Enterprises was relatively popularized in small-sized enterprises in Shandong Province. The enterprises implementing Accounting Standards for Business Enterprises have carried out adjustment in financial account according to rules, with obvious performance in financial information; besides, they have obtained good reputation from relevant customers and partners.

1.2. Inevitable trend for implementation of accounting standard in middle and small-sized enterprises

The former CPC General Secretary Hu Jintao once mentioned in 18th Party Congress: today, under the condition of market economy, the appearance of some middle and small-sized enterprises promotes economic development and brings brand-new thoughts for Chinese future direction of economic development. As is known to us, under the influence of previous economic crisis, the economic development is not smooth and there still exists certain barrier in economic recovery; under this background, the development of middle and small-sized enterprises is also influenced; besides, there also exist shortcomings in middle and small-sized enterprises, which makes the development and expansion of middle and small-sized enterprises face challenge. Then, in order to obtain healthy sustainable development, the middle and small-sized enterprises shall draw support from social power, and the corresponding legal regulations are necessary; the legal regulations such as Accounting Standards for Small-sized Enterprises not only can standardize the healthy development and middle and small-sized enterprises, but also can bring much guidance. At the initial implementation stage of legal regulations, some barriers must be met, and it is required to summarize experience through continuous practice, and combine with the specific accounting situation of middle and small-sized enterprises to make legal regulations become more perfect and obtain better guidance practice as well as make enterprises develop towards better direction.

\section{Survey and research on implementation situation of accounting standard of small-sized enterprises in Shandong province}

\subsection{Method of survey}

In order to better know the influence of issuance of Accounting Standards for Small-sized Enterprises on small-sized enterprises, enterprise accounting personnel's mastering degree of new standard and problems which may happen in implementation process, this paper adopts questionnaire way to carry out survey on small-sized enterprises for the purpose of obtaining some conclusions. The questionnaire includes two parts. One part is basic condition of small-sized enterprises, such as enterprise scale, main business, and annual fiscal revenue. As for another part, the questionnaire is designed from two aspects, that is, implementation quality of accounting standard and supporting implementation. In questionnaire survey, this paper selects enterprise accounting personnel's familiarity to accounting standard, process operation, proportion of qualified implementation of standards in actual accounting work, and enterprise leaders' awareness to implementation standard of accounting standards as the evaluation factor for qualified implementation of accounting standard, and those evaluation factors have certain representativeness and feasibility of actual operation.

The setting of questionnaire survey is finally determined according to important degree of evaluation factor. As for each evaluation, the author sets evaluation of five degrees. As for importance of each item, there is a ranking of five different degrees. Take personnel's familiarity to accounting standard as an example: as for this evaluation factor, there are three aspects of evaluation, that is, "familiar", "relatively familiar", and "not familiar", in terms of degree. As for evaluation, the three evaluations "familiar", "relatively familiar", and "not familiar" are scored as 3, 2, 1 respectively. The qualified degree questionnaire survey is released to small-sized enterprises in Shandong province; there are totally 150 questionnaires issued, including 140 effective questionnaires, with an effective rate of 93.33\%. 


\subsection{Defects of system}

Accounting System for Small-sized Enterprises has defects, which are mainly reflected as follows:

Firstly, the applicable scope is unclear.

Accounting System for Small-sized Enterprises stipulates that it is mainly applicable for some enterprises; however, it doesn't specify the scale of small-sized enterprises and specific range, which brings many inconveniences for implementation of system. The applicable scope is: "the enterprises which are established in the territory of the People's Republic of China with no external capital raising and small operation scale; besides, no external capital raising refers to not public issuance of stock or bond, but not including loan from bank or other financial institutions". However, this system gives no definition for the phenomenon that partial companies have subsidiaries, which makes such type of companies have an embarrassed condition. Furthermore, many large-scale companies have established branches in Shandong province, and such type of companies is a team which can't be ignored. Meanwhile, this system also gives no definition for some individual private enterprises and directly marks them out the scope, which violates from reality. Therefore, the operation personnel in the accounting work have no idea about which standard is most suitable, which directly causes a chaotic situation.

Secondly, the difference between system and tax law is not coordinated well.

As for some small-sized enterprises, they pay same attention to seeking quantity of information. The main window for enterprises to obtain information is tax department. The fact that the tax department takes information demand of small-sized enterprise as an index of its information systemizing and release is inevitable. Accounting System for Small-sized Enterprises also realizes the importance of this point and gradually tries different points between them. However, in reality, the implementation of accounting process and diversity of tax law are still very large, which results in a situation that the relevant work staff have large quantity of unnecessary task load in the declaration. For example, in terms of selection of depreciation method, depreciation life, and net residual value of fixed assets, the requirements of tax law can meet the features of small-sized enterprises. Accounting System for Small-sized Enterprises can utilize the features of tax law such as strong operability so that it can be more suitable for enterprise demand.

Thirdly, no connecting rules are made.

Accounting System for Small-sized Enterprises mainly sets some rules about conventional events; however, it gives no stipulations for few businesses with low frequency of occurrence. This also causes many loopholes, and the accounting personnel can't find suitable standard in specific implementation. The rules belong to principle orientation and have no detailed and specific guidance, thus they are difficultly implemented. Meanwhile, a timely adjustment is sometimes made on the accounting system, and the unclear connecting rules result in great inconvenience in actual implementation of middle and small-sized enterprises.

\section{To formulate reasonable solution}

\subsection{To enhance propaganda and training on new standard}

In the implementation process of Accounting Standard, it is hard to implement the Accounting Standard due to the fact that many professional work personnel get no deep knowledge or master bad skills, and then various problems caused therefrom are inevitable. In order to better solve corresponding problems, relevant departments shall organize large quantity of accounting training so as to penetrate relevant knowledge of Accounting Standard into financial work personnel's work; certainly, the propaganda and guide are also required through various methods and means. If necessary, the force of propaganda can be expanded, such as reasonable propaganda via media and forum. As for specific propaganda, it is required to combine with means with "affectionate to the people" property; when the financial work staff carries out corresponding work, it is able to organize temporary professional knowledge education training and establish reliable network communication platform so that the accounting personnel can preview relevant items of Accounting Standard and matters which they need pay attention to; in this way, it is able to create an active and 
progressive professional knowledge training environment and form a kind of benign circulation. In the process of social external training, the active and effective support and coordination from relevant government finance departments are required.

The relevant professional personnel engaging in accounting work have insufficient knowledge reserve; this is not because they have a bad working enthusiasm, but lack of a learning stage for new things. As for this situation, the relevant management department shall pay attention to coordination, and it is able to add Accounting Standard into accounting courses to carry out standard teaching; the relevant personnel of each management department shall also take further education, know professional knowledge, and add professional literacy for convenience of closer communication with trainees. In a same classroom, it is required to carry out active interaction and joint learning; faced with corresponding small-sized enterprises, it is required to organize partial work staff of management layer to have management training so as to form integration of internal management and operation of enterprises. In training process, the management department shall actively coordinate relevant considerations, such as source of internship force and matching scheme of faculty. It is better to employ teachers from colleges with strong specialty and good professional quality, and then make a reasonable assignment on teachers; the assignment shall follow balance principle. Besides, the practice part shall be added into curriculum design process; if the learning content has too many theories, the trainees' learning initiative will be discouraged; the learning process is boring, which influences learning efficiency. The addition of practice link can effectively solve this malpractice and make personnel get hold of professional knowledge and reasonably utilize them in collaborative practice activity. Before end of course completion, a professional assessment shall be made, and the personnel with qualified scores pass the training; otherwise they shall retake the courses so as to make trainees pay more attention to it.

3.2. The enterprises shall make preparation well

The small-sized enterprises in Shandong province have certain local features, while the accounting standard is formulated on a national scope. Therefore, the enterprises shall also make some fundamental corresponding work to do some basic affairs well.

Firstly, the corresponding change shall be made for introduction standard of accounting talent, and the enterprises shall take accounting personnel's familiarity to accounting standard as one of evaluation factors. Only superficial theoretical knowledge can't meet actual demand, and more attention shall be paid to talents' accurate operation and understanding in actual operation. As for enterprises, in order to better implement new standard, the following preparations shall be made: learning and training; formulating business accounting method of enterprise; property verification; accounting adjustment; system updating.

Secondly, the enterprise leaders' knowledge comprehensiveness shall be also enhanced; in particular, company CEO shall also get certain knowledge of accounting standard. The director of financial department shall have strong knowledge utilization ability and basic awareness of strictly abiding by accounting standard so as to penetrate those basic opinions into enterprises' actual things. Partial enterprises with strong features shall place corresponding staff into suitable business accounting or other work link according to their own actual situation to form an independent implementation network.

\section{Conclusion}

Currently, the Accounting Standard for Small-sized Enterprises will be implemented comprehensively less than 10 months later; the departments at all levels of Shandong province are actively making preparation, enhancing leadership, and making careful organization and wide training so as to ensure smooth implementation of Accounting Standard for Small-sized Enterprises. In specific implementation, the tracing guidance shall be also made for relevant part, and some close attention shall be paid to specific accounting implementation personnel so as to master actual implementation lifeline of enterprise. Through a series of above discussion, it can be easily found that the implantation of high-quality accounting talents is very important for enterprises; both large-sized and small-sized enterprises shall have accounting standard implementation network with 
its own features. The finance department with perfect functions for small-sized enterprises is an irresistible trend; through work staff's unremitting efforts and active cooperation of relevant management department, a good performance is obtained in terms of fiscal system of small-sized enterprises. However, new problems also happen accordingly; through theory learning, the corresponding professional skills can be utilized in a mature way, and various violation and even illegal behaviors happen continuously; as for such phenomenon, Shandong government arranges the relevant management department to carry out management and rectification, as well as restraint and supervision according to Chinese relevant legal regulations about accounting. The key points in next few years will be supervision and support on finance department of small-sized enterprises.

\section{Acknowledgments}

This paper is a social science planning project (accounting project) of Shandong province. Project name: Relevant Problems in Implementation of Accounting Standards for Business Enterprises and Accounting Standards for Small-sized Enterprises - Research on Implementation Environment and Effectiveness Evaluation; project No.: 13CKJJ16; school-level project name of Shandong Yingcai University: Research on Implementation Problems of Accounting Standards for Small-sized Enterprises in Shandong Province; project No.: 12 YCYBRW01.

\section{References}

[1] Nie Lv: Implementation Situation of New Accounting Standard in Chinese Listed Companies [J], China Collective Economy, 2009 (07).

[2] Journalist, correspondent: Research on Implementation Situation of Standard [J], China Asset Appraisal, 2009(06).

[3] Gai Di, Li Xiuyu, Du Jingran: Analysis on Implementation of Accounting Standards for Business Enterprises by Non-listed Companies - based on data of questionnaire survey [J], Journal of Yunnan University of Finance and Economics, 2010 (01).

[4] Liang Laixin, Jin Yang: Research on Disclosure of R\&D Expenses of Chinese Listed Companies - based on survey on information disclosure of listed companies after implementation of new standard [J], Journal of Yunnan University of Finance and Economics, 2010 (03).

[5] Li Yue, Peng Yuan, Shi Shengkun: Analysis on Implementation Situation of New Accounting Standard and Countermeasure Research - based on survey on large and middle-sized enterprises in Beijing City [J], Securities \& Futures of China, 2010 (10)

[6] Cai Qiliang: Analysis on Implementation Situation of New Accounting Standards by Listed Companies on Small and Medium-sized Enterprises Board [J], Securities Market Herald, 2007 (07) 